\title{
Vitamin D in critically ill patients
}

\author{
Katarzyna Matysiak-Luśnia \\ $2^{\text {nd }}$ Department of Anaesthesiology and Intensive Therapy, University Hospital in Wrocław, Poland \\ Clinic for Home Parenteral and Enteral Nutrition, Regional Specialist Hospital, Jelenia Góra, Poland
}

\begin{abstract}
Vitamin D deficiency is a commonly observed global phenomenon, both in the general population and in hospitalized patients, including critically ill patients. Vitamin D deficiency is associated with multiple adverse health outcomes, including increased morbidity and mortality in the general population and in critically ill patients. Vitamin D is a fatsoluble vitamin that plays an important role in bone metabolism. However, Vitamin D is also a steroid hormone that exerts multiple pleiotropic effects. Vitamin D regulates immunity, inflammation, cell proliferation, differentiation, apoptosis, and angiogenesis. There is growing evidence of a close relationship between vitamin D insufficiency and various systemic disorders, i.e., type II diabetes, certain types of cancer, obesity, and cardiovascular morbidities. The purpose of this article is to present the current knowledge on the relationship between vitamin D status and critical illness.
\end{abstract}

Key words: vitamin D, critical illness, intensive care, critically ill

Anaesthesiology Intensive Therapy 2016, vol. 48, no 3, 201-207

There is mounting evidence of the role of vitamin $D$ in blood serum as a factor determining the course and prognosis of numerous diseases. Knowledge of the molecular basis of vitamin D action, its extraosseous effects and its significant role in the prevention and treatment of chronic diseases, especially inflammatory diseases, is growing. This paper presents the current state of knowledge regarding vitamin $D$, particularly its role in critically ill patients treated in intensive care units (ICUs).

\section{PRODUCTION AND METABOLISM OF VITAMIN D}

Vitamin $D$ belongs to the group of steroid chemical compounds with the general formula $\mathrm{C}_{28} \mathrm{H}_{43} \mathrm{OH}$. The group contains vitamin D1 (a mixture of cholecalciferol and lumisterol occurring in cod liver oil, a compound with a similar structure as vitamin D but without the same activity), vitamin D2 (ergocalciferol) and vitamin D3 (cholecalciferol). Vitamin D2 occurs in plants, whereas vitamin D3 is produced in human and animal skin, mainly in the keratocytes of the proliferative epithelium, mediated by ultraviolet radiation (specifically UVB radiation). The compounds are activated in the liver by hydroxylation to 25-hydroxyderivatives and subsequently in other organs to 1,25-dihydroxyderivatives. The latter conversion occurs primarily in the kidneys and is mediated by parathormone (PTH). Calcitriol (1,25-dihydroxycholecalciferol) is an active form of vitamin D3, a substance of hormonal action regulating many organs and tissues. Although the metabolic effects of vitamin D2 and vitamin D3 are similar, they bind with different types of plasma proteins. As a result, the action of vitamin D3 is longer and 2-10-fold more effective than vitamin D2.

Vitamin D3 is one of a few vitamins that the body is able to produce endogenously; therefore, it does not fulfil the definition of a vitamin. Ultraviolet radiation is required for the production of Vitamin D3 in the body, more specifically UVB (wavelength of $280-315 \mathrm{~nm}$ ), which enables the conversion of skin 7-dehydrocholesterol (provitamin D3) into cholecalciferol (vitamin D3). The metabolism of vitamin D3 is presented in Figure 1.

Vitamin D3 can also be derived from foods, such as milk, butter, fish and some mushrooms.

For simplification, the term "vitamin $D$ ", referring to the group of compounds, will be used instead of "vitamin D3" in the remainder of the paper.

The production of sufficient amounts of vitamin $D$ by the body is affected by geographic and environmental factors. These factors include the latitude, season, atmospheric conditions, sun height, translucency of the atmosphere, 


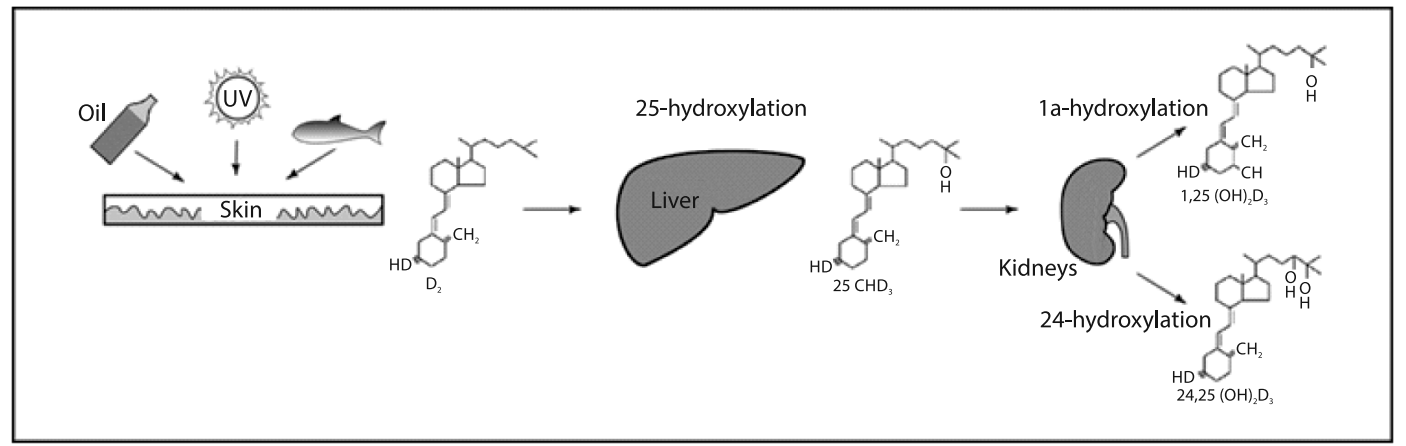

Figure 1. Metabolism of vitamin D3

Table 1. Diagnostic criteria for vitamin D intakes for adults. According to [7]

\begin{tabular}{|c|c|c|c|}
\hline & \multicolumn{2}{|c|}{$\begin{array}{l}\text { Concentration of } 25(\mathrm{OH}) \mathrm{D} \\
\text { in serum }\end{array}$} & \multirow[t]{2}{*}{ Interventions to consider } \\
\hline & $\mathrm{nmol} \mathrm{L} \mathrm{L}^{-1}$ & $\mathrm{ng} \mathrm{mL} \mathrm{m}^{-1}$ & \\
\hline Deficiency & $0-50$ & $0-20$ & Deficiency therapy \\
\hline Suboptimal concentration & $>50-75$ & $>20-30$ & Increase/maintenance of vitamin D supplementation \\
\hline Optimal concentration & $>75-125$ & $>30-50$ & Maintenance of vitamin D supplementation \\
\hline High concentration & $>125-250$ & $>50-100$ & Maintenance/decrease of vitamin D doses \\
\hline Potentially toxic concentration & $>250$ & $>100$ & Abstinence from vitamin D intake until optimal concentration of $25(\mathrm{OH}) \mathrm{D}$ is reached \\
\hline Toxic concentration & $>500$ & $>200$ & Treatment of potential toxic effects \\
\hline
\end{tabular}

cloudiness, time spent in closed spaces, and type of clothing, which may limit the amount of sunlight reaching the skin surface. Moreover, the percentage of radiation dispersed in total solar radiation is essential. Additionally, any changes in the quantity of UVB photons reaching the skin can significantly affect the dermal production of vitamin D. In winter, sunrays fall at a right angle in the early mornings and afternoons, which is unfavourable for the synthesis of vitamin $D$. The UVB photons are absorbed by the atmospheric ozone, and the dermal production of vitamin $D$ is limited. According to Webb and colleagues [1], the intensity of vitamin D production in the skin during winter and at latitudes above $35^{\circ} \mathrm{N}$ and below $35^{\circ} \mathrm{S}$ is almost undetectable.

One essential factor affecting the dermal synthesis of vitamin $D$ is age; the content of 7-dehydroxycholesterol in the skin has been found to be negatively correlated with age [2]. The amount of melanin in the skin could decrease by 5 to 10 times. Limited skin surface exposure to UVB radiation and creams with sun protection factors (SPFs) reduce the skin synthesis of vitamin D. A cream with SPF 8 reduces the ability to synthesize vitamin D by $95 \%$ [3].

In Poland, the values of direct sun radiation recorded most commonly are within the range of $600-800 \mathrm{~W} \mathrm{~m}^{-2}$. In the hottest summer period, the value of sun exposure reaches $1200 \mathrm{~W} \mathrm{~m}^{-2} ; 80 \%$ of total annual solar radiation occurs during the six months of the spring-summer season (from the beginning of April to the end of September).

Deficiencies of vitamin D are common in the Polish climatic zone and in Europe. Despite the guidelines regarding vitamin $D$ supplementation proposed by many scientific societies from various countries, the deficiency of vitamin $D$ remains common in all age ranges and in different populations [4-6]. In 2013, a team of experts formulated and published "Practical guidelines for the supplementation of vitamin D and the treatment of deficits in Central Europe - recommended vitamin $D$ intakes in the general population and groups at risk of vitamin D deficiency" [7]. These guidelines contain recommendations for all age groups and for some specific populations, e.g., pregnant and lactating women, and recommendations regarding maximum safe doses for healthy individuals (Tables 1,2) and the doses used for treatment (Table 3) and supplementation (Table 4).

\section{PLEIOTROPIC ACTION OF VITAMIN D}

In recent years, attention has been focused on the nonskeletal effects of vitamin D, i.e., its pleiotropic actions inducing various effects that are sometimes very distant and difficult to connect. A biologically active vitamin D, i.e., calcitriol, belongs to the superfamily of hormones and directly modulates the activity of many genes. Calcitriol binds the 
Table 2. Maximum daily doses of vitamin D recommended by the European Food Safety Authority. According to [7]

\begin{tabular}{lc}
\hline Newborns and infants & $1000 \mathrm{IU} \mathrm{d} \mathrm{d}^{-1}\left(25 \mu \mathrm{g} \mathrm{d}^{-1}\right)$ \\
Children aged 1-10 years & $2000 \mathrm{IU} \mathrm{d} \mathrm{d}^{-1}\left(50 \mu \mathrm{g} \mathrm{d}^{-1}\right)$ \\
Children and teenagers aged 11-18 years & $4000 \mathrm{IU} \mathrm{d}^{-1}\left(100 \mu \mathrm{g} \mathrm{d}^{-1}\right)$ \\
Adults and elderly people with normal body weight & $4000 \mathrm{IU} \mathrm{d} \mathrm{d}^{-1}\left(100 \mu \mathrm{g} \mathrm{d}^{-1}\right)$ \\
Obese adults and obese elderly people & $10,000 \mathrm{IU} \mathrm{d} \mathrm{d}^{-1}\left(250 \mu \mathrm{g} \mathrm{d}^{-1}\right)$ \\
Pregnant and lactating women & $4000 \mathrm{IU} \mathrm{d}^{-1}\left(100 \mu \mathrm{g} \mathrm{d}^{-1}\right)$ \\
\hline
\end{tabular}

Table 3. Recommended therapeutic doses of vitamin D. According to [7]

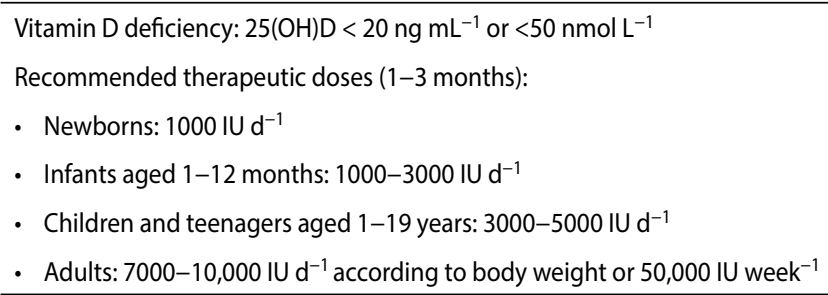

Table 4. Doses of vitamin D recommended for healthy adult populations. According to [7]

\author{
Adults $>18$ years of age and the elderly \\ 800-2000 IU d $\mathrm{d}^{-1}$ according to body weight from September to April \\ 800-2000 IU d ${ }^{-1}$ according to body weight throughout the year, when effective dermal synthesis of vitamin D is not provided during summer months \\ Elderly individuals (65+) 800-2000 IU d $\mathrm{d}^{-1}$ according to body weight throughout the year due to reduced capacity for dermal synthesis of vitamin D
}

vitamin D receptor (VDR) and subsequently DNA, regulating the activity of approximately $5 \%$ of the human genome (500 genes), which indicates its pleiotropic effects. Unlike in cases of other hormones from this superfamily, such as glucocorticosteroids, mineral corticosteroids, progesterone, androgens or oestrogens, the synthesis of calcitriol is directly limited by the availability of a substrate, i.e., $25(\mathrm{OH}) \mathrm{D}$ (calcidiol). Calcidiol is a metabolite produced in the liver from native vitamin $D$. The essence of adequate substitution of vitamin $D$ is the provision of optimal amounts of $25(\mathrm{OH}) \mathrm{D}$ for the synthesis of the hormonally active form, $1,25(\mathrm{OH})_{2} \mathrm{D}$, in all target tissues [8].

Under certain circumstances, the nuclear receptors of vitamin $D$ can be translocated to the mitochondria of some cells, thus directly affecting the activity of the oxygen chain and energy metabolism of cells. This process occurs in platelets, megakaryocytes, macrophages and other cells. In many diseases (type 2 diabetes, metabolic syndrome, neoplastic and cardiovascular diseases), which are characterized by the persistence of chronic inflammation, the dysfunction of mitochondria and impaired energy function of cells are fundamental. Vitamin D deficiency is associated with impaired intracellular homeostasis of calcium and regulation of oxidative phosphorylation. Vitamin $D$, by binding VDR translocated to a mitochondrion, can modulate the inflow of calcium ions to the mitochondria or directly affect the activation of vitamin D-dependent genes [9]. The mechanism of the anti-inflammatory effects of vitamin $D$ most likely involves weakening the activation of p38, blocking $\mathrm{NF}-\kappa \mathrm{B}$ activation and reducing concentrations of matrix metalloproteinases.

The receptors for calcitriol were found in the organs involved in maintaining mineral homeostasis, such as the intestine, bone, kidney or parathyroids, and in other tissues and organs, e.g., immune cells, pancreatic $\beta$ cells, or muscular tissues. Within the immune system, vitamin $D$ exerts multi-directional effects, stimulating the function of macrophages, T lymphocytes, activated B lymphocytes, maturation of dendritic cells, modulation of TNF expression and production of neutral antibacterial peptides, i.e., cathelicidins and $\beta$-defensin. Cathelicidins are constitutively produced by many cells involved in the mechanisms of innate immunity, such as neutrophils, NK cells, mast cells and numerous epithelial cells [10], particularly the epithelial cells of the airway, gingiva, urinary bladder and gastrointestinal system, i.e., the cells in direct continuous contact with external pathogens. Moreover, the synthesis of cathelicidins was observed in dendritic cells, monocytes/macrophages and 
lymphocytes. In keratinocytes and monocytes, the expression of the cathelicin-encoding gene is regulated by the biologically active vitamin D metabolite (calcitriol), which is a ligand of nuclearVDR. The synthesis of cathelicidins is stimulated by bacterial infections and potent proinflammatory cytokines (TNF- $\alpha$, IL-1, IL-6, and interferon $\gamma$ ). Cathelicidins recruit leucocytes, induce chemotaxis of immunocompetent cells to the infection sites, cause degradation of walls of immunologically foreign cells and biofilm, and bind lipopolysaccharide residues. Moreover, cathelicidins are involved in the inhibition of lipopolysaccharide-dependent activation of the endothelium and vasodilatation. Before antibiotics, vitamin D was used to treat tuberculosis, and its metabolites are found to be active against Mycobacterium in vitro [11]. There is also evidence that low pre-hospitalization levels of vitamin D are correlated with the incidence of Clostridium difficile and bloodstream infections during hospitalization [12, 13]. In the extra-hospital population, low levels of vitamin $D$ are positively correlated with the incidence and severity of respiratory infections [14]. In some viral infectious diseases, (e.g., influenza), low concentrations of vitamin D can be a risk factor of infection or its more severe course [15].

$\beta$-defensin 4 stimulates innate immunity by direct antibacterial activity in phagosomes and phagolysosomes. The activation of Toll-like receptors $2 / 1$ on monocytes results in vitamin D-dependent activity directed against intracellular pathogens [16].

Furthermore, the antineoplastic effects of vitamin D have been recently implicated and are associated with the biological activity of neoplasms and the ability to inhibit cell proliferation and to regulate cell differentiation. The antineoplastic action of $1,25(\mathrm{OH})_{2}$-cholecalciferol is most likely mediated by VDR affecting the gene expression [17]. Bound to its natural ligand, i.e., VDR, active vitamin D enhances apoptosis of neoplastic cells and, as a transcription factor, regulates the activity of more than 60 genes responsible for cell differentiation, antiproliferative effects and inhibition of angiogenesis. Numerous epidemiological studies have demonstrated that the most common forms of cancer, such as breast, colon, rectal, uterine, ovarian cancers and lymphatic leukaemia, are negatively correlated with the serum levels of vitamin D. Vitamin D is also involved in the development of metabolic syndrome, type I diabetes, arterial hypertension, rheumatoid arthritis, and multiple sclerosis. A concentration of $25(\mathrm{OH}) \mathrm{D}_{3}$ within the range of $80 \mathrm{nmol} \mathrm{L}^{-1}$ or higher has preventive effects. According to a meta-analysis published in 2011 , the risk of colon cancer decreases by $15 \%$ with an increase in plasma concentration of vitamin $\mathrm{D}$ by $10 \mathrm{ng} \mathrm{mL}^{-1}$ on average [18]. The substitution of vitamin D is recommended in early breast cancer cases [19].

The kinetics of activity of the calcitriol-synthesizing 1- $\alpha$ hydroxylase enzyme suggest that the optimal serum con- centration of $25(\mathrm{OH}) \mathrm{D}$ should be $40 \mathrm{ng} \mathrm{mL}^{-1}\left(100 \mathrm{nmol} \mathrm{L}^{-1}\right)$. The rate of $1,25(\mathrm{OH})_{2} \mathrm{D}$ synthesis reaches half of its maximum value at a $25(\mathrm{OH}) \mathrm{D}$ concentration of $40 \mathrm{ng} \mathrm{mL}^{-1}\left(100 \mathrm{nmol} \mathrm{L}^{-1}\right)$. The effects of calcitriol on the enterocytes, increasing the absorption of calcium from the gastrointestinal tract, are most effective at a concentration of $25(\mathrm{OH}) \mathrm{D}$ exceeding $30 \mathrm{ng} \mathrm{mL}^{-1}$. Beneficial clinical effects, e.g., enhanced immunity and reduced risk of cardiovascular, autoimmune and neoplastic diseases, are observed at a serum concentration of $25(\mathrm{OH}) \mathrm{D}$ of $30-50 \mathrm{ng} \mathrm{mL}^{-1}$, which provides proper conditions for adequate synthesis of $1,25(\mathrm{OH})_{2}$ vitamin $\mathrm{D}$ in all body compartments.

\section{SIGNIFICANCE OF VITAMIN D IN ICU PATIENTS}

Vitamin D deficiency is common in the general population and in ICU patients. The deficiency is associated with impaired calcium-phosphate metabolism and with bone metabolism and leads to secondary hyperparathyroidism, which results in mobilization of calcium from the skeleton to maintain its serum concentration within normal limits. ICU patients, especially those undergoing long-term treatment, are at risk of numerous causes of vitamin D deficiency, such as earlier deficiency, immobilization, lack of adequate exposure to sunlight, malnutrition, increased conversion of $25(\mathrm{OH})$ vitamin $\mathrm{D}$ to $1,25(\mathrm{OH})_{2}$ vitamin $\mathrm{D}$, inflammation, and liver or kidney failure. Pleiotropic effects of vitamin D on the immune system, epithelia, glucose metabolism, and calcium homeostasis are essential in critically ill patients. ICU patients, particularly those undergoing long-term treatment, often suffer from osteoporosis, immunological dysfunction, changes in body composition (loss of muscle mass, increase in the adipose tissue) or neurohumoral disorders, which significantly hinders their rehabilitation and recovery.

Hypocalcaemia is common in ICU patients, despite strict hormonal monitoring to maintain the serum calcium concentrations within narrow physiological ranges. In addition to rarer causes of hypocalcaemia, such as massive transfusions, post-thyroidectomy parathyroid failure, acute pancreatitis, alkalosis or some drugs, vitamin D deficiency is its likely, frequent and underestimated cause. Hypocalcaemia positively correlates with the incidence of complications in ICU patients, APACHE II score and mortality [20]. Supplementation of calcium appears to be a beneficial therapeutic option in ICUs. However, a Cochrane systematic review has not justified this practice [21]. Considering the above findings, the substitution of vitamin $D$ could be one therapeutic option. Unfortunately, vitamin D deficiency is rarely recognized, is even less frequently treated in ICUs and is an underestimated issue.

The minimum desirable concentration of vitamin D in ICU patients is likely to be within the range of 20 to $30 \mathrm{ng} \mathrm{dL}^{-1}$ [22]. According to estimates, the incidence of vitamin $D$ defi- 
ciency in the population of critically ill patients ranges from $17 \%$ to $79 \%$ [23-25].

Due to the ubiquity of VDR, widespread expression of $1-\alpha$-hydroxylase and its effects on apoptosis and cellular differentiation, vitamin D could significantly affect atherosclerosis, cardiovascular diseases, circulatory and respiratory failure, sepsis and other disorders typical in critically ill patients [26]. Therefore, the hypothesis that vitamin D deficiency is a potentially modifiable risk factor in critically ill patients appears logical.

In contrast to the extra-hospital population, in which the lowest concentrations of vitamin $D$ are associated with increased overall mortality [27], the data regarding a correlation between the concentration of $25(\mathrm{OH}) \mathrm{D}$ and prognosis are inconsistent. The cause and effect analysis is undoubtedly hindered by widespread deficiency of vitamin D in many populations, including a considerably differentiated population of critically ill patients, and by the fact that patients with multiple organ failure and sepsis have lower concentrations of vitamin D-binding protein (DBP), which could cause hypovitaminosis $D$ in this group of patients. Polymorphisms of DBP and of the enzymes responsible for the activation and degradation of vitamin $\mathrm{D}$ and its metabolites are also affected by serum concentrations of $25(\mathrm{OH}) \mathrm{D}$ [28].

The studies available reveal a correlation between low levels of $25(\mathrm{OH}) \mathrm{D}$ and short- and long-term mortality rates in ICU patients (on day 30, 90 and 365), increased risks of sepsis [29,30], cardiac failure, critical illness myopathy, hyperglycaemia and impaired microcirculation [31]. The findings, reported by Amrein and colleagues [32], have revealed that the vast majority (87\%) of ICU patients had low or very low concentrations of vitamin $D$, which was positively correlated with mortality. The study carried out by Venkatram and colleagues [33] demonstrated a correlation between the concentration of $25(\mathrm{OH}) \mathrm{D}$ in patients in a multi-specialized ICU and hospital mortality. Extremely low levels of vitamin D were found in $77 \%$ of patients. Azim and colleagues [34] did not observe a correlation between the concentration of vitamin D and mortality. According to a study published in 2015 of 10 Dutch general intensive care units involving approximately 1,400 patients, vitamin D deficiency on admission was observed in less than $38 \%$ of cases. Vitamin D deficiency on admission was associated with higher incidences of sepsis, higher APACHE II scores and longer hospitalization, yet was not clearly correlated with mortality [35]. In the study conducted by van der Berghe et al. [36], intravenous supplementation of vitamin D in patients hospitalized in ICUs for a long time did not lead to increased serum concentrations of vitamin D or resulted in its increase, which did not affect the patient's condition. According to one study, the vitamin D supplementation had beneficial effects on critically ill patients [37].
The strongest known correlation between vitamin $D$ metabolites and the immune system results from the effects of vitamin D on the production of cathelicidins. In animal models, the deficiency of cathelicidins has been associated with a higher susceptibility to bacterial infections, whereas overexpression has been connected with antibacterial protection [38, 39]. In humans, the only known cathelicidin with antibacterial potential is the human cathelicidin antimicrobial protein hCAP18. Both $25(\mathrm{OH})$ vitamin D and 1,25(OH) vitamin D induce the production of hCAP18 in vitro in immune cells (neutrophils, monocytes, macrophages) and in many other cells, e.g., epithelial cells and keratinocytes [40, 41]. Having assumed significant immunomodulatory and antibacterial effects of vitamin D, Leaf and colleagues [42] administered calcitriol to sepsis and septic shock patients at a dose of $2 \mu \mathrm{g}$ i.v. vs. placebo. These authors did not find statistically significant changes in the concentrations of cathelicidins and markers of inflammation (IL-10, IL-6, TNF- $\alpha$, IL-1 $\beta$, IL-2). Nevertheless, lower concentrations of $25(\mathrm{OH})$ vitamin $\mathrm{D}$ on day 1 of ICU treatment correlated with low levels of hCAP18 and a higher risk of death on day 90. The study in question involved a small group of patients; according to the authors, further multi-centre randomized studies are required [43]

Increased mortality in population of critically ill patients with vitamin $D$ deficiency could be associated with disorders of calcium and glucose metabolism and with immunological dysfunction of the endothelium [44]. Endothelial dysfunction is likely to be the cause of multiple organ dysfunction syndrome; moreover, vitamin D deficiency, by enhancing metabolic and immunological disorders, could contribute to a worse prognosis in critically ill patients, particularly patients with sepsis. These disorders include immunosuppression, impaired chemotaxis, phagocytosis and increased production of antibacterial cathelicidins.

Tarcin and colleagues [45], comparing selected parameters in a group of patients with asymptomatic vitamin D deficiency with data from individuals with normal levels of vitamin $D$, demonstrated that vitamin $D$ deficiency is associated with increased peroxidation of lipids and endothelial dysfunction. The supplementation of vitamin $D$ beneficially affected the studied parameters of endothelial function.

In several interventional studies carried out in ICU patients, various doses of vitamin D (200 IU to 540,000 IU) with a saturating dose or otherwise, different forms (cholecalciferol, calcitriol), different administration routes (enteral, parenteral), and different treatment durations were applied. The scientific societies do not specifically refer in their recommendations to the ICU patient population $[46,47]$. An initial dose ranging from 50,000 to $60,000 \mathrm{IU}$, depending on the baseline patient's condition and body weight, should be considered [48]. However, due to possible severe complica- 
tions after very high doses of vitamin D, e.g., hypercalcaemia, hypercalciuria, extraosseous calcifications and kidney calcifications, such doses cannot be routinely recommended for critically ill patients without further studies [49].

The most promising outcomes of the treatment of vitamin D deficiency in critically ill patients have been reported by Amrein et al. [50]. Their one-centre double-blind, placebo-controlled randomized clinical trial VITdAL involved almost 500 individuals. Although a negative outcome was found at the primary final point (length of hospitalization), beneficial effects have been demonstrated (higher chances of survival, NNT 6) in patients with very low levels of $25(\mathrm{OH})$ $\mathrm{D}\left(\leq 12 \mathrm{ng} \mathrm{mL}^{-1}\right.$ ) who received 540,000 IU of cholecalciferol, followed by $90,000 \mathrm{IU}$ a month over the next 5 months. The group with such a high vitamin D deficiency included 200 individuals, i.e., $42 \%$ of the study population. The doses of vitamin $\mathrm{D}$ used in the study were undoubtedly pharmacological but not physiological [50].

Both the initial dose and further doses, as well as the administration routes, raise doubts. The majority of ICU patients have contraindications for intramuscular injections, and intravenous preparations containing high doses of vita$\min \mathrm{D}$ are not available. With the enteral forms, uncertainty of intestinal absorption, impaired peristalsis and circulatory efficiency within the intestine should be considered. Moreover, the coexistence of sepsis and multiple organ failure should be considered.

The intravenous vitamin preparations commonly used for substitution contain small doses of vitamin $D$, which correspond to the daily doses for healthy people recommended earlier. The doses of some vitamins (C, D, B1) are insufficient to meet the requirements of critically ill patients. Cernevit ${ }^{\oplus}$ Baxter, a multivitamin preparation, contains 220 IU of vitamin D3, whereas Vitalipid N Adult ${ }^{\oplus}$ FreseniusKabi contains 200 IU of vitamin D2, which is inconsistent with the recommendations for the healthy population. In enteral diets, the content of vitamin $D$ is standard and may not cover the requirements at low serum doses of vitamin $D$, particularly in ICU patients with impaired absorption and tolerance of enteral nutrition.

The recommendations for vitamin D substitution in healthy individuals with vitamin $\mathrm{D}$ deficiency should probably assume its supply at a dose between 1000 and 10,000 IU a day. Such doses should enable the target concentration to be reached within 2-3 months.

Some groups require special attention, i.e., monitoring of serum vitamin $D$ levels and tailoring a substitutive dose based on the findings. These groups include patients with renal dysfunction, malabsorption syndrome, those receiving anticonvulsants and obese individuals.

A different strategy is required to optimize the serum concentrations of vitamin D in critically ill patients. The standard methods of substitution do not provide effective treatment of hypovitaminosis/avitaminosis $D$ in this group of patients. A high saturating dose ranging from 50,000 IU to 600,000 IU should be considered, depending on the baseline concentration of vitamin $D$ and the body weight. Further large-scale studies are necessary to confirm the efficacy of such therapies and the absence of adverse effects.

Oral and enteral supply could be effective in ICU patients due to malabsorption caused by gastrointestinal oedema and inflammation. The unpredictable process of absorption, changes in hydroxylation (impaired renal function), transport of vitamin D and degradation of its metabolites (impaired hepatic function) hinder treatment via the gastrointestinal tract. Moreover, increased vitamin D requirements at the tissue level are of importance, which leads to enhanced conversion of $25(\mathrm{OH}) \mathrm{D}$ into $1,25(\mathrm{OH})_{2} \mathrm{D}$. An intravenous form of vitamin D3 would be ideal; unfortunately, this form is not available.

There are no explicit data from multi-centre randomized studies demonstrating a correlation between vitamin D deficiency, prognosis and mortality in ICU patients. The available guidelines lack specific recommendations for the critically ill patient population. The same is true about the updated Canadian Clinical Practice Guidelines (published as the "Summary of Recommendations" on www.criticalcarenutrition.com on May $\left.25^{\text {th }}, 2015\right)$. Nevertheless, there are numerous potential beneficial effects of vitamin $D$, which is likely to be used in future in the therapy of critically ill patients. Notably, the standard diets and multi-vitamin preparations available on the market contain insufficient amounts of vitamin D to meet the increased demand and to correct vitamin D hypovitaminosis.

Because of financial limitations and an underestimation of the problem, concentrations of vitamins, including vitamin $D$, are not determined or are rarely determined, predominantly in cases of suspected anaemia or osteoporosis. Considering the available data indicating the extraosseous, pleiotropic effects of vitamin $D$, special attention should be paid to its deficiency in ICU patients.

\section{ACKNOWLEDGMENTS}

1. Financial support: none.

2. Conflict of interest: none.

\section{References:}

1. Webb AR, Kline L, Holick MF: Influence of season and latitude on the cutaneous synthesis of vitamin D3: exposure to winter sunlight in Boston and Edmonton will not promote vitamin D3 synthesis in human skin. J Clin Endocrinol Metab 1988; 67: 373-378.

2. MacLaughlin J, Holick MF: Aging decreases the capacity of human skin to produce vitamin D3. J Clin Invest 1985; 76: 1536-1538.

3. Matsuoka LY, Ide L, Wortsman J, MacLaughlin JA, Holick MF: Sunscreens suppress cutaneous vitamin D3 synthesis. J Clin Endocrinol Metab 1987; 64: 1165-1168. 
4. Holick MF, Binkley NC, Bischoff-Ferrari HA et al:: Evaluation, Treatment, and Prevention of Vitamin D Deficiency: an Endocrine Society Clinical Practice Guideline. J Clin Endocrinol Metab 2011; 96: 1911-1930.

5. DobrzańskaA;ZespółEkspertów: Polskie zalecenia dotyczące profilaktyki niedoborów witaminy D. 2009.

6. Charzewska J, Chlebna-SokółD, Chybicka A et al.: Prophylaxis of vitamin $\mathrm{D}$ deficiency-Polish recommendation 2009. Endokrynol Pol 2010; 61: 228-232.

7. Płudowski P, Karczmarewicz E, Bayer $M$ et al.: Practical guidelines for the supplementation of vitamin $D$ and the treatment of deficits in Central Europe - recommended vitamin D intakes in the general population and groups at risk of vitamin D deficiency. Endokrynol Pol 2013; 64: 319-327.

8. Płudowski P, Kryśkiewicz E, Karczmarewicz E: Zasady suplementacji i standardy oceny zaopatrzenia organizmu w witaminę D w świetle jej działania plejotropowego. Borgis - Postępy Nauk Medycznych 2012; 3: 265-272.

9. Calton $E K$, Keane $K N$, Soares $M J$ :The potential regulatory role of vitamin $\mathrm{D}$ in the bioenergetics of inflammation. Curr Opin Clin Nutr Metab Care 2015; 18: 367-373. doi: 10.1097/MCO.0000000000000186.

10. Witkowska D, Bartyś A, Gamian A: Defensyny i katelicydyny jako naturalne antybiotyki peptydowe. Postępy Hig Med Dosw 2008; 62: 694-707.

11. Martineau AR, Timms PM, Bothamley GH et al.: High-dose vitamin $\mathrm{D}(3)$ during intensive-phase antimicrobial treatment of pulmonary tuberculosis: a double-blind randomised controlled trial. Lancet 2011; 377: 242-250.

12. Lange N, Litonjua AA, Gibbons FK, Giovannucci E, Christopher KB: Prehospital vitamin $D$ concentration, mortality, and bloodstream infection in a hospitalized patient population. Am J Med 2013; 126: 640 e619-627. doi: 10.1016/j.amjmed.2012.12.014.

13. Quraishi SA, Litonjua AA, Moromizato $T$ et al.: Association between prehospital vitamin $D$ status and hospital-acquired Clostridium difficile infections. J Parenter Enteral Nutr 2015; 39: 47-55 doi: 10.1177/0148607113511991.

14. Remmelts HH, van de Garde EM, Meijvis SC et al.: Addition of vitamin $D$ status to prognostic scores improves the prediction of outcome in community-acquired pneumonia. Clin Infect Dis 2012; 55: 1488-1494. doi: 10.1093/cid/cis751.

15. Urashima $M$, Segawa T, Okazaki $M$, Kurihara $M$, Wada Y, Ida H: Randomized trial of vitamin D supplementation to prevent seasonal influenza A in schoolchildren. Am J Clin Nutr 2010; 91: 1255-1260. doi: 10.3945/ ajcn.2009.29094.

16. Liu PT, Schenk $M$, Walker VP et al.: Convergence of IL- $1 \beta$ and VDR Activation Pathways in Human TLR2/1-Induced Antimicrobial Responses. PLoS ONE 2009; 4(6): e5810 2009; doi: 10.1371/journal.pone.0005810.

17. Doroszko A, Gronowicz E: Cholekalcyferol a procesy wzrostu i różnicowania komórek - znaczenie w terapii onkologicznej. Onkol Pol 2008; 11: 15-18.

18. Ma Y, Zhang P, Wang F, Yang J, Liu Z, Qin H: Association between vitamin $D$ and risk of colorectal cancer: a systematic review of prospective studies. J Clin Oncol 2011; 29: 3775-3782. doi: 10.1200/JCO.2011.35.7566.

19. Coates AS, Winer EP, Goldhirsch A et al.: Tailoring therapies - improving the management of early breast cancer: St Gallen International Expert Consensus on the Primary Therapy of Early Breast Cancer 2015. Ann Oncol (2015) doi: 10.1093/annonc/mdv221.

20. Zivin JR, Gooley T, Zager RA, Ryan MJ: Hypocalcemia: a pervasive metabolic abnormality in the critically ill. Am J Kidney Dis 2001; 37:689-698. doi: http: //dx.doi.org/10.1016/S0272-6386(01)80116-5.

21. Forsythe RM, Wessel CB, Billiar TR, Angus DC, Rosengart MR: Parenteral calcium for intensive care unit patients. Cochrane Database Syst Rev 2008; CD006163. doi: 10.1002/14651858.CD006163.pub2.

22. Bischoff-FerrariHA, GiovannucciE, WillettWC, Dietrich T, Dawson-Hughes B: Estimation of optimal serum concentrations of 25-hydroxyvitamin $D$ for multiple health outcomes. Am J Clin Nutr 2006, 84: 18-28, Review. Erratum in: Am J Clin Nutr 2006, 84: 1253.

23. Lucidarme $O$, Messai E, Mazzoni T, Arcade M, du Cheyron D: Incidence and risk factors of vitamin $D$ deficiency in critically ill patients: results from a prospective observational study. Intensive Care Med 2010, 36: 1609-1611.

24. Lee P, Eisman JA, Center JR: Vitamin D deficiency in critically ill patients. N Engl J Med 2009; 360: 1912-1914. doi: 10.1056/NEJMc0809996.

25. McKinney JD, Bailey BA, Garrett LH, Peiris P, Manning T, Peiris AN: Relationship between vitamin D status and ICU outcomes in veterans. J Am Med Dir Assoc 2011; 12: 208-211. doi: 10.1016/j.jamda.2010.04.004.

26. Zittermann $A$ :Vitamin $D$ and disease prevention with special reference to cardiovascular disease. Prog Biophys Mol Biol 2006, 92: 39-48.

27. Schöttker $B$, Jorde $R$, Peasey $A$ et al.: Vitamin D and mortality: metaanalysis of individual participant data from a large consortium of cohort studies from Europe and the United States. BMJ 2014; 348: g3656. doi: 10.1136/bmj.g3656.

28. Ahn J, YuK, Stolzenberg-Solomon Ret al.: Genome-wide association study of circulating vitamin D levels. Hum Mol Genet 2010; 19: 2739-2745. doi: $10.1093 / \mathrm{hmg} / \mathrm{ddq} 155$.
29. Braun A, Chang D, Mahadevappa K et al: Association of low serum 25-hydroxyvitamin D levels and mortality in the critically ill. Crit Care Med 2011; 39: 671-677. doi: 10.1097/CCM.0b013e318206ccdf.

30. Moromizato T, Litonjua AA, Braun AB, Gibbons FK, Giovannucci E, Christopher KB: Association of low serum 25-hydroxyvitamin D levels and sepsis in the critically ill. Crit Care Med 2014; 42: 97-107. doi: 10.1097/ CCM.0b013e31829eb7af.

31. Lee P, Nair P, Eisman JA, Center JR: Vitamin D deficiency in the intensive care unit: an invisible accomplice to morbidity and mortality? Intensive Care Med 2009; 35: 2028-2032. doi: 10.1007/s00134-009-1642-x.

32. Amrein K, Zajic P, Schnedl Ch et al.: Vitamin D status and its association with season, hospital and sepsis mortality in critical illness. Crit Care 2014; 18: R47. doi: 10.1186/cc13790.

33. Venkatram S, Chilimuri S, Adrish M, Salako A, Patel M, Diaz-Fuentes G: Vitamin $D$ deficiency is associated with mortality in the medical intensive care unit. Crit Care 2011; 15: R292. doi: 10.1186/cc10585.

34. Azim A, Ahmed A, Yadav S et al.: Prevalence of vitamin D deficiency in critically ill patients and its influence on outcome: experience from a tertiary care centre in North India (an observational study). Intensive Care 2013; 1: 14. doi: 10.1186/2052-0492-1-14.

35. De Haan K. Low serum 25-hydroxyvitamin D at critical care initiation is associated with sepsis and morbidity in Dutch critically ill patients. Critical Care 2015; 19 (Suppl 1): P365; doi: 10.1186/cc14445.

36. Van den Berghe $G$, Van Roosbroeck D, Vanhove P, Wouters PJ, De Pourcq L, Bouillon R: Bone turnover in prolonged critical illness: effect of vitamin D. J Clin Endocrinol Metab 2003; 88: 4623-4632.

37. Mata-Granados JM, Vargas-Vasserot J, Ferreiro-Vera C, Luque de Castro $M D$, Pavon RG, Quesada Gomez JM: Evaluation of vitamin D endocrine system (VDES) status and response to treatment of patients in intensive care units (ICUs) using an on-line SPE-LC-MS/MS method. J Steroid Biochem Mol Biol 2010; 121:452-455. doi: 10.1016/j.jsbmb.2010.03.078.

38. Nizet $V$, Ohtake $T$, Lauth $X$ et al.: Innate antimicrobial peptide protects the skin from invasive bacterial infection. Nature 2001; 414: 454$-457$.

39. Bals $R$, Weiner $D J$, Moscioni AD, Meegalla RL, Wilson JM: Augmentation of innate host defense by expression of a cathelicidin antimicrobial peptide. Infect Immun 1999; 67: 6084-6089.

40. Liu PT, Stenger S, Li H et al.: Toll-like receptor triggering of a vitamin D mediated human antimicrobial response. Science 2006; 311 : 1770-1773.

41. Yim S, Dhawan P, Ragunath C, Christakos S, Diamond G: Induction of cathelicidin in normal and CF bronchial epithelial cells by 1,25-dihydroxyvitamin D(3). J Cyst Fibros 2007; 6: 403-410.

42. Leaf DE, Raed A, Donnino MW, Ginde AA, Waikar SS: Randomized controlled trial of calcitriol in severe sepsis. Am J Respir Crit Care Med 2014; 190: 533-541. doi: 10.1164/rccm.201405-09880C

43. Leaf DE, Croy HE, Abrahams SJ, Raed A, Waikar SS: Cathelicidin antimicrobial protein, vitamin $D$, and risk of death in critically ill patients. Crit Care 2015; 19: 80. doi: 10.1186/s13054-015-0812-1.

44. Burchard KW, Gann DS, Colliton J, Forster J: Ionized calcium, parathormone, and mortality in critically ill surgical patients. Ann Surg 1990; 212: 543-549.

45. Tarcin O, Yavuz DG, Ozben B et al.: Effect of vitamin D deficiency and replacement on endothelial function in asymptomatic subjects. J Clin Endocrinol Metab 2009; 94: 4023-4030. doi: 10.1210/jc.2008-1212.

46. Kreymann KG, Berger MM, Deutz NE et al.: ESPEN Guidelines on enteral nutrition: intensive care. Clin Nutr 2006, 25: 210-223.

47. Singer $P$, Berger $M M$, van den Berghe $G$ et al.: ESPEN Guidelines on parenteral nutrition: intensive care. Clin Nutr 2009; 28: 387-400. doi: 10.1016/j.clnu.2009.04.024.

48. Munns C, Zacharin MR, Rodda CP et al.: Prevention and treatment of infant and childhood vitamin D deficiency in Australia and New Zealand: a consensus statement. Med J Aust 2006; 185: 268-272.

49. Joshi R: Hypercalcemia due to hypervitaminosis D: report of seven patients. JTrop Pediatr 2009; 55: 396-398. doi: 10.1093/tropej/fmp020.

50. Amrein K, Schnedl C, Holl A et al.: Effect of high-dose vitamin D3 on hospital length of stay in critically ill patients with vitamin $D$ deficiency: the VITdAL-ICU randomized clinical trial. J Am Med Assoc 2014; 312: 1520-1530. doi: 10.1001/jama.2014.13204.

\section{Corresponding author:}

Katarzyna Matysiak-Luśnia

$2^{\text {nd }}$ Department of Anaesthesiology and Intensive Therapy,

University Hospital in Wrocław

T. Chałubińskiego 1a, 50-368 Wrocław, Poland

e-mail:mi_anest@op.pl

Received: 18.09 .2015

Accepted: 18.03.2016 